\title{
Ultrastructural Changes Accompanying the Mechanical Deformation of Bone Tissue: A Raman Imaging Study
}

\author{
A. Carden, ${ }^{1}$ R. M. Rajachar, ${ }^{2,3}$ M. D. Morris, ${ }^{1}$ D. H. Kohn ${ }^{2,3}$ \\ ${ }^{1}$ Department of Chemistry, University of Michigan, Ann Arbor, Michigan 48109-1078, USA \\ ${ }^{2}$ Department of Biologic and Materials Sciences, University of Michigan, Ann Arbor, Michigan 48109-1055, USA \\ ${ }^{3}$ Department of Biomedical Engineering, University of Michigan, Ann Arbor, Michigan 48109-2125, USA
}

Received: 12 April 2002 / Accepted: 1 July 2002 / Online publication: 10 December 2002

\begin{abstract}
Raman spectroscopy and imaging are known to be valuable tools for the analysis of bone, the determination of protein secondary structure, and the study of the composition of crystalline materials. We have utilized all of these attributes to examine how mechanical loading and the resulting deformation affects bone ultrastructure, addressing the hypothesis that bone spectra are altered, in both the organic and inorganic regions, in response to mechanical loading/deformation. Using a cylindrical indenter, we have permanently deformed bovine cortical bone specimens and investigated the ultrastructure in and around the deformed areas using hyperspectral Raman imaging coupled with multivariate analysis techniques. Indent morphology was further examined using scanning electron microscopy. Raman images taken at the edge of the indents show increases in the low-frequency component of the amide III band and high-frequency component of the amide I band. These changes are indicative of the rupture of collagen crosslinks due to shear forces exerted by the indenter passing through the bone. However, within the indent itself no evidence was seen of crosslink rupture, indicating that only compression of the organic matrix takes place in this region. We also present evidence of what is possibly a pressure-induced structural transformation occurring in the bone mineral within the indents, as indicated by the appearance of additional mineral factors in Raman image data from indented areas. These results give new insight into the mechanisms and causes of bone failure at the ultrastructural level.
\end{abstract}

Key words: Raman - Bone - Biomechanics - Spectroscopic imaging — Fracture

Like most tissues, bone is hierarchical in structure [1]. Any study of bone properties must investigate the tissue at several levels of organization in order to gain a complete understanding of the influence of structure and composition on these properties. This is especially true when studying mechanical properties. Many studies have looked at the effect of applied load on bone, but on

Correspondence to: M. D. Morris; E-mail: dhkohn@, umich.edu, and D. H. Kohn; E-mail: dhkohn@umich.edu a macroscopic level [1]. A few have looked at a lower, microstructural level; for example, studies of microcracking [2-4], tensile properties of single osteons [5], and nanoindentation studies of individual lamellae [6, 7]. However, studies at an ultrastructural or chemical level have been impossible using the most common techniques. As a result of these limitations, it is not known definitively how individual collagen fibrils or mineral crystallites react to mechanical load in either the elastic or plastic deformation regimes. There are many hypotheses - rupture of crosslinks in the collagen fibrils, mineral phase transformations or rearrangements, separation of fibrils, and/or relative motion ("gliding") of fibrils $[8,9]$. However, new technical approaches are needed to address these hypotheses and to study the ultrastructural mechanisms guiding the response of bone to mechanical loading.

In recent years, vibrational spectroscopy has enjoyed increasing success as a technique for studying bone properties [10]. Infrared and Raman spectroscopies have been used to study normal and osteoporotic tissue, as well as to investigate compositional changes associated with various bone diseases [10-13]. Raman spectroscopy has proven particularly useful because of its ability to be used on intact specimens as well as its lack of strong interferences from water. Raman spectra can be collected with micron-scale spatial resolution and give simultaneous information about the mineral and organic matrix components of bone. Raman spectra can also be collected over a two-dimensional area to give spatially relevant image information. With the use of multivariate statistics, small local variations in bone composition can be resolved [14-16]. Information from the mineral component and the organic matrix is obtained simultaneously, creating a complete picture of bone composition in the area surveyed. The phosphate $v_{1}$ band at approximately $960 \mathrm{~cm}^{-1}$ and the bands associated with collagen (amide III at $\sim 1250 \mathrm{~cm}^{-1}, \mathrm{CH}_{2}$ wag at $\sim 1450$ $\mathrm{cm}^{-1}$, and amide I at $\sim 1665 \mathrm{~cm}^{-1}$ ) are of particular interest for bone compositional studies [10]. 


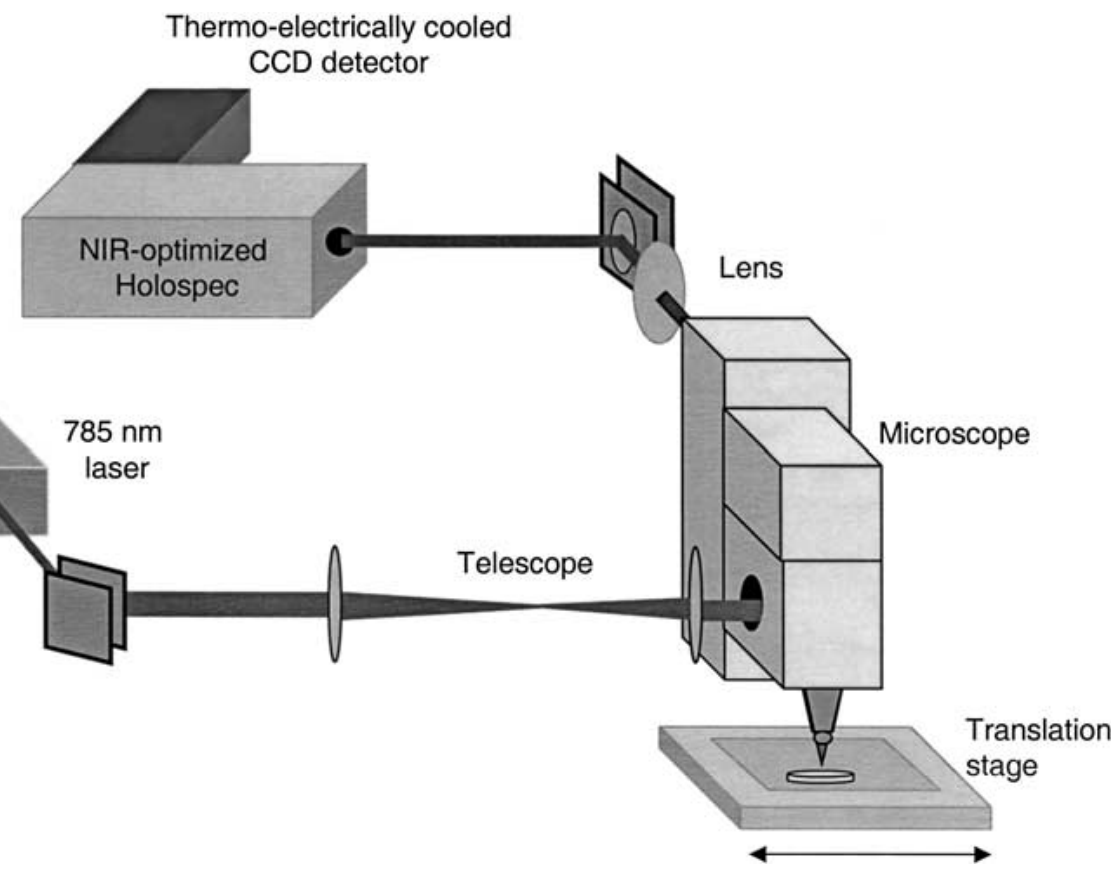

Fig. 1. Raman imaging apparatus.

Raman spectroscopy is a well-established technique for looking at changes brought on by mechanical loading in such materials as polymers $[17,18]$ and protein films [19], as well as changes in protein structure in solution [20]. Generally, structural changes induced by an applied load cause shifts in bands in the Raman spectrum [1719]. The amide I band, at about $1665 \mathrm{~cm}^{-1}$, and the amide III band, at about $1250 \mathrm{~cm}^{-1}$, are known to be especially good indicators of protein conformation because of the amide moiety's role in crosslinking and bonding [21]. Spectra of crystalline materials such as silicon or calcium hydroxyapatite also show shifts in spectral bands with applied load, presumably as a result of pressure-induced rearrangement of the crystalline lattice [22-25].

Recent experiments in this lab using Raman spectroscopy have started to provide insight into damage mechanisms at the ultrastructural level. Increases in the number of mineral factors (phosphate $v_{1}$ spectral components) have been observed at the leading edge of fatigue-induced microcracks in cortical bone [14]. It was not clear from these studies whether the spectroscopic changes were a cause or an effect of the damage. Subsequent studies, which analyzed spectral changes in realtime during compressive and tensile loading of bone, provided support for the hypothesis that spectral shifts result from mechanical damage, and demonstrated that changes in the organic matrix also result from mechanical loading [26]. In the present study, we address the hypothesis that bone spectra are altered, in both the organic and inorganic regions, in response to mechanical loading/deformation.

We report here the results of experiments on bovine tissue that was mechanically loaded and locally deformed via cylindrical indentation. Our results show that most of the damage to the organic matrix occurs at the edges of indents rather than in the center. This damage is in the form of ruptured cross-links, as indicated by spectroscopic shifts in amide I and amide III bands. Additionally, there is evidence that mineral structural transitions are occurring within the indented areas, as evidenced by the increased numbers of mineral factors obtained from the analysis of Raman image data from these regions relative to control areas. These results support the hypothesis that additional mineral factors observed in areas of damage are an effect rather than a cause of the damage.

\section{Materials and Methods}

\section{Specimens}

Bovine bone from skeletally mature animals was obtained from a local abattoir. A section from the lateral anterior portion of the central annulus of a femur was milled into a flat rectangular beam approximately $3 \mathrm{~cm} \times 1 \mathrm{~cm} \times 15 \mathrm{~cm}$ and stored frozen at $-64^{\circ} \mathrm{C}$. For these experiments, the beam was cut into 4 pieces, 1 of which was reserved for a separate experiment and was not used further in these studies. The remaining specimens were polished on one side using a graded series of grits, followed by a $0.3 \mu \mathrm{m}$ alumina slurry. The specimens were sonicated briefly to remove any particles and were then placed in a calcium-buffered antibacterial saline solution. Storage in such solutions at concentrations previously determined to maintain equilibrium has been found to maintain bone mechanical properties by minimizing the diffusion of calcium from the tissue [27]. The specimens were stored at $4^{\circ} \mathrm{C}$ until needed.

\section{Indentations}

Cylindrical indentations were made with a custom-built cylindrical indenter tip attached to an Instron servo-hydraulic 


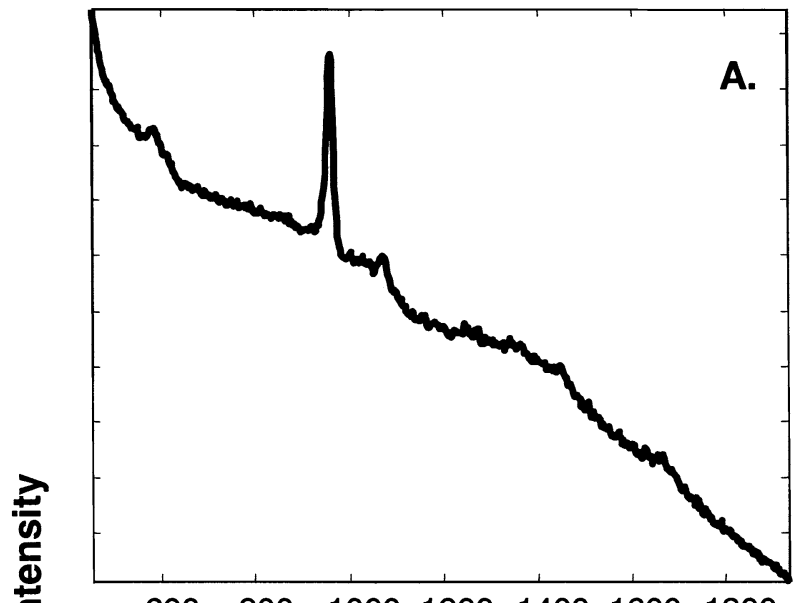

$600 \quad 80010001200140016001800$

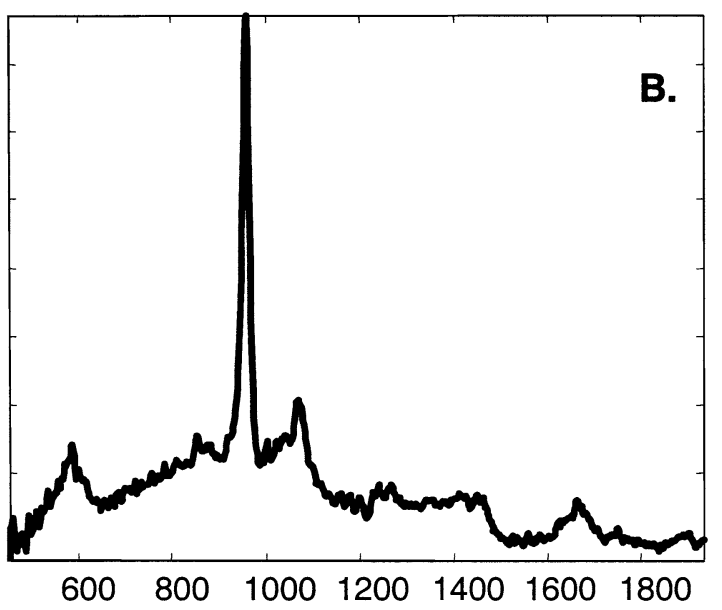

\section{Raman shift, $\mathbf{c m}^{-1}$}

Fig. 2. Advantages of factor analysis: signal-to-noise improvement and background removal. (A) Raw Raman spectrum of bone from one of the image data sets discussed in this work. (B) Factor, representing the Raman spectrum of bone, derived from factor analysis of the entire image data set (approximately 3100 spectra total). For clarity, additional background factors resulting from luminescence are not shown.

mechanical testing machine (model 8521). Using a cylindrical indenter is useful for spectroscopic imaging purposes because the floor of the indent is flat, allowing spectroscopic investigation within the indent as well as at its edges. Indentations resulting from two different loads were made upon each specimen. The shallower (low load) indents (approximate depth $10 \mu \mathrm{m}$ ) were made with loads ranging from 70 to $110 \mathrm{~N}$, and the loads for the deeper (high load) indents (approximate depth $100-150 \mu \mathrm{m})$ were in the range of $230-240 \mathrm{~N}$.

\section{Raman Imaging}

Our Raman imaging system (Fig. 1) has been previously described $[14,16,28,29]$. Briefly, it consists of a $785 \mathrm{~nm}$ external cavity diode laser (Kaiser Optical Systems, Inc.) with a highaspect-ratio rectangular beam profile. The beam size is reduced using a telescope and the beam is coupled into a modified epifluorescence microscope (Olympus, Inc.). A $10 x / 0.5 \mathrm{NA}$ objective (Zeiss) focuses the line-shaped laser beam (length $\sim 200$ $\mu \mathrm{m})$ onto the specimen. A complete Raman spectrum is collected simultaneously from every point along the line by the objective, focused by a collection lens, and directed into an axial-transmissive spectrograph (Kaiser Optical Systems, Inc.) which disperses the Raman scatter. The signal is then detected by a thermo-electrically cooled CCD camera (Andor Technologies, Inc.) and stored on a personal computer. A twodimensional image is built up by moving the specimen in approximately $1 \mu \mathrm{m}$ steps under the laser beam using a translation stage (New England Affiliated Technologies, Inc.) and acquiring a new line of spectra at each new stage position. An image data set thus consists of a matrix with every point containing a complete Raman spectrum.

For these studies, Raman images were taken in three locations for each indent: within the indent on the indent floor, at the very edge of the indent on the bone surface, and at least $500 \mu \mathrm{m}$ outside the indent area. A total of 18 images ( 3 images/ indent $\times 2$ indents/specimen $\times 3$ specimens) were obtained. Each image contained 25 lines of spectra; the approximate size of each area imaged was $200 \times 35 \mu \mathrm{m}$. The total laser power at the specimen was approximately $230 \mathrm{~mW}$, spread into a rectangle approximately $200 \mu \mathrm{m}$ long and $6 \mu \mathrm{m}$ wide. It should be noted that because of the shape of the laser beam, power density is relatively low, and heat dissipation is highly efficient [30]. Heat damage to mineralized tissue specimens of the size used in this study has not been observed with this technique [31].

\section{Data Analysis}

Both univariate and multivariate analysis techniques were used to examine the data. A spectroscopic parameter proportional to the mineral-to-organic-matrix ratio was used. Similar parameters have been frequently employed by infrared spectroscopists [13, 32]. This spectroscopic mineral-to-organicmatrix ratio was calculated for all of the areas imaged by dividing the spectra from each image into 10 random groups, calculating the mean spectrum from each group, fitting this mean spectrum to a third-order polynomial to remove the effects of luminescent background, then dividing the maximum height of the phosphate $v_{1}$ band at $\sim 959 \mathrm{~cm}^{-1}$ by the maxi mum height of the $\mathrm{CH}_{2}$ wag band at $\sim 1450 \mathrm{~cm}^{-1}$. The $\mathrm{CH}_{2}$ wag band was chosen since it is less likely than the amide bands to change shape or shift due to changes in protein structure caused by applied load [33]. Ten mineral-to-organicmatrix ratio values were generated for each image, and a standard deviation was calculated from these 10 values.

Factor analysis was also performed on each image data set. Factor analysis is a well-established multivariate image analysis technique [34] used in such fields as magnetic resonance imaging [35-37] and fluorescence imaging [38]. We have frequently used this data analysis approach for the analysis of Raman spectroscopy and image data [39-41]. In this technique, the data are considered as matrices with one spatial and one spectral dimension. The covariance matrix of this matrix is calculated, and a singular value decomposition is performed to obtain the eigenvalues and eigenvectors of the covariance matrix. The eigenvectors can then be combined in linear combinations (or "rotated") using non-negativity and bandshape constraints to produce Raman spectra. This is not a random process. Spectra cannot be created by rotation; however, they can be separated from backgrounds very effectively. In addition, because factor analysis is an averaging technique, the signal-to-noise ratio in factors is generally significantly better than in raw spectra (Fig. 2). Factor analysis is useful for separating species that may have overlapping spectra, but differ in their spatial distributions. Thus, if two species have different spectra but identical spatial distributions, their spectra will not be separated.

Once the eigenvectors (now called factors) have been effectively rotated, each individual factor's distribution in the area surveyed can be calculated by regressing the factors back onto the data. The resulting image is called a score image and 

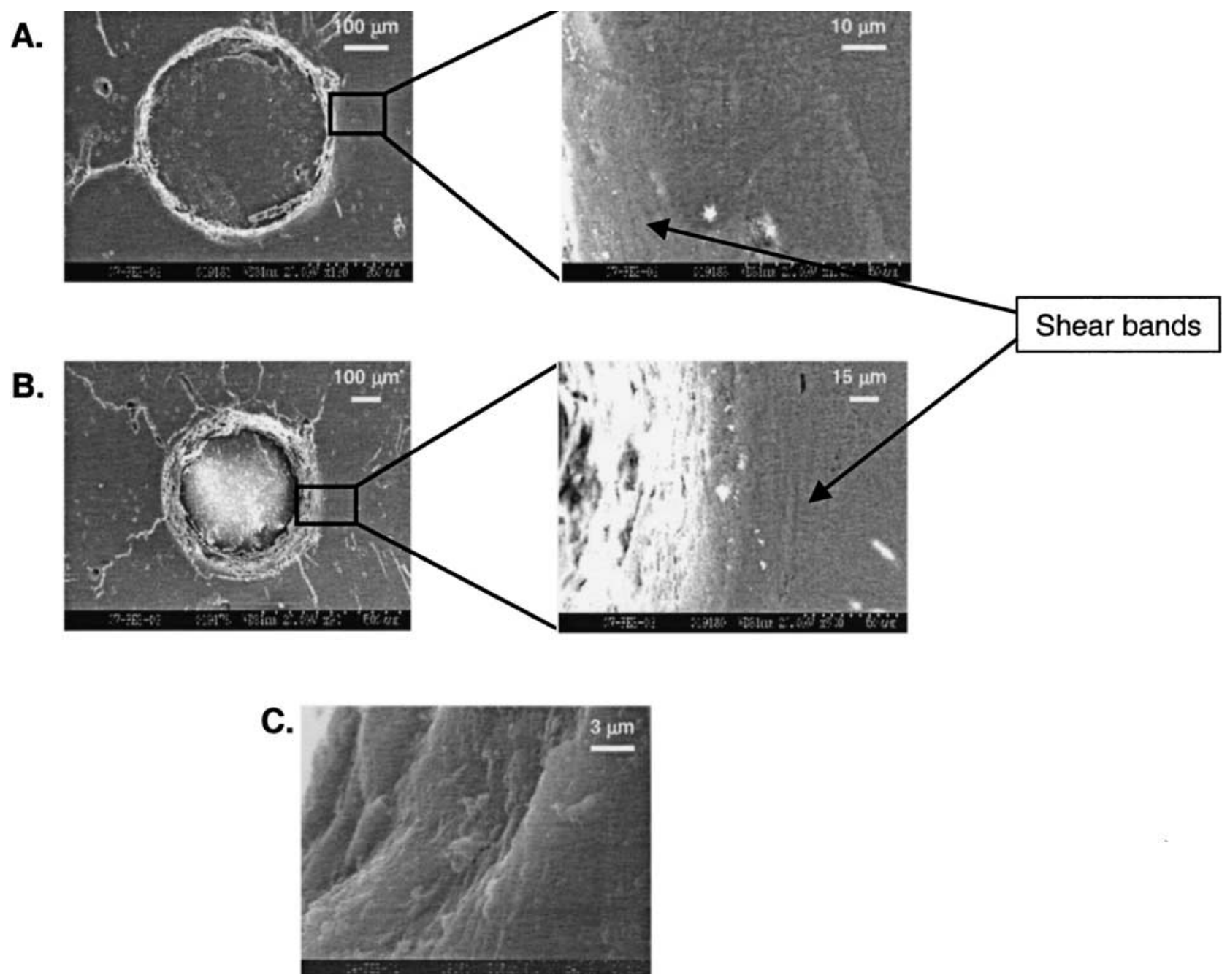

Fig. 3. SEM images of cylindrical indents. (A) Low-load indent on specimen \#3. Note the shear bands visible in the highmagnification image on the right. (B) High-load indent on the same specimen. Again, shear bands are visible in the higher-

is a plot of the spatial distribution of factor intensity within the area imaged.

For these experiments the image data were divided into two spectral subregions: a "mineral subregion" (approximately $500-1200 \mathrm{~cm}^{-1}$ ) containing the most intense and characteristic bands of the mineral components, and an "organic matrix subregion" (approximately 1200-1800 $\mathrm{cm}^{-1}$ ) containing the most intense bands attributable to the collagenous matrix. Each spectral subregion was analyzed separately. Factor analysis was performed in MATLAB software (Mathworks, Inc.); both vendor-supplied and locally written scripts were used.

\section{SEM Imaging}

Indentation specimens were prepared for SEM analysis with a thin coating of colloidal carbon for electron conductivity. A Hitachi S3200N Scanning Electron Microscope was used for all imaging under conventional high-vacuum mode and secondary electron scintillator detection mode. The electron beam energy was kept at $20 \mathrm{kV}$ and the operating distance was adjusted to $15 \mathrm{~mm}$. Digital images were captured and stored with Quartz PCI acquisition software. magnification image. Shear-induced radial cracking is also visible in both lower-magnification images. (C) High-magnification view of shear bands along the indent wall.

\section{Results}

\section{SEM Images}

Images of both low- and high-load indents clearly showed shear bands around the circumference of the indent, indicating the presence of shear forces caused by the indenting process (Fig. 3).

\section{Mineral-to-Organic-Matrix Ratio}

The spectroscopic mineral-to-organic-matrix ratio for image areas was calculated in order to confirm that the areas imaged were comparable in terms of composition, and that any changes we observed were a result of mechanical loading and deformation, not compositional variations. Because Raman band intensity varies linearly with the number of scattering centers, the phosphate $v_{1} / \mathrm{CH}_{2}$ wag band height ratio is proportional to the 

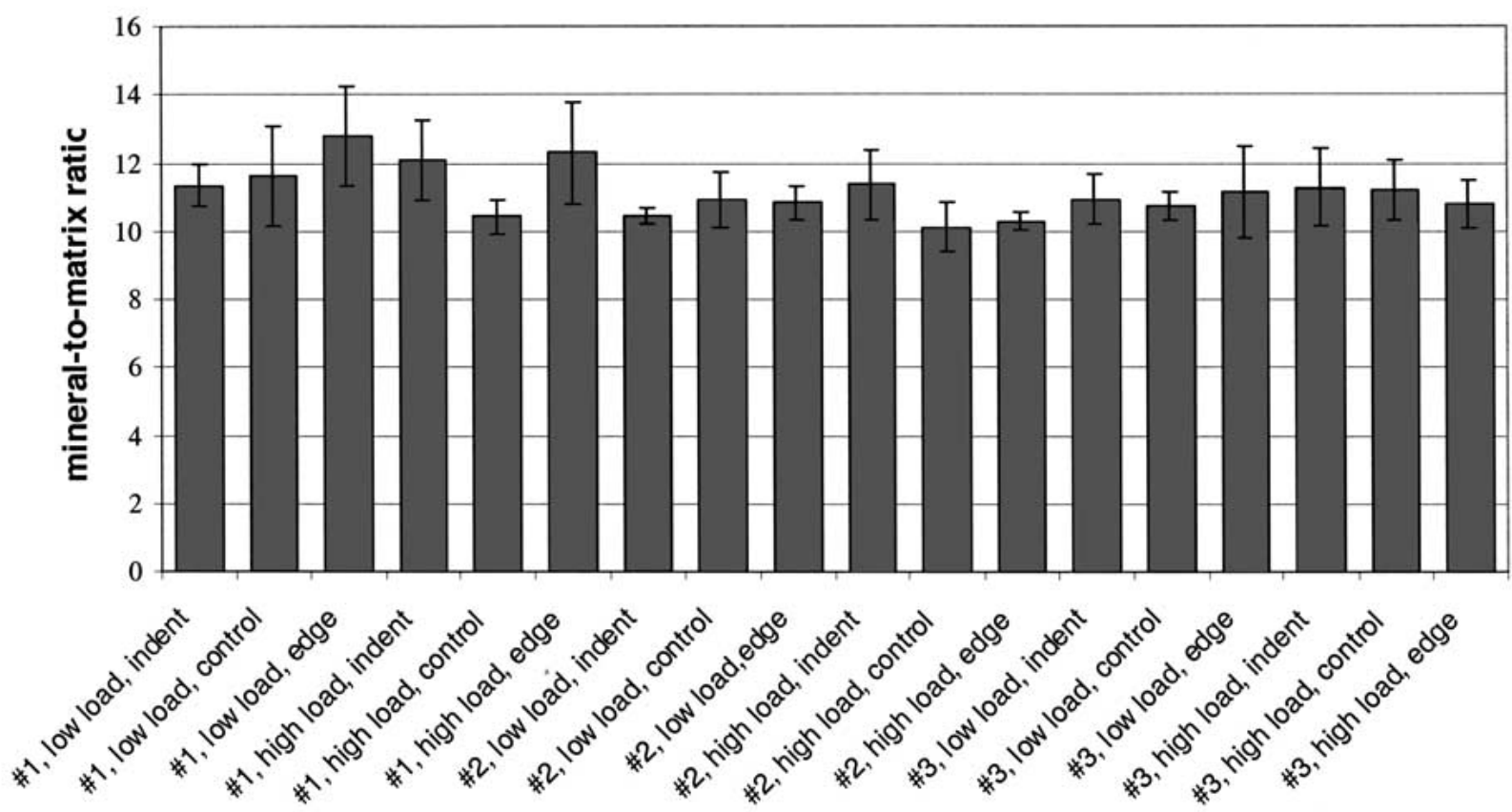

Fig. 4. Bar graph of spectroscopic mineral-to-organic-matrix ratio (phosphate $v_{1}$ maximum intensity divided by $\mathrm{CH}_{2}$ wag band maximum intensity) calculated for all areas imaged. Error bars are \pm 1 SD.

chemical mineral-to-organic-matrix ratio. Figure 4 shows a bar graph of the calculated mineral-to-organicmatrix values for all the areas imaged. The values are relatively consistent. Two-way ANOVA revealed that while there were no statistically significant differences between any of the areas on specimens 2 and 3 $(P<0.05)$, specimen 1 was significantly different from the other two specimens in the edge and indent areas. It should be noted that there were no statistically significant differences in the spectroscopic mineral-toorganic-matrix ratio among the widely spaced control areas on any of the specimens $(P<0.207)$. Statistical variations in the indent and edge regions therefore could be the result of damage resulting from the indent process. Based on these results, we concluded that the differences in spectroscopic mineral-to-organic-matrix ratio among the three specimens were not significant, and that comparisons among the different specimens were valid.

\section{Factor Analysis: Organic Matrix Subregion}

In all images of control areas and areas within indentations, only one organic matrix factor was observed (Fig. 5). This factor contained the bands commonly observed in Raman spectra of bone organic matrix [10]: the amide III band at $\sim 1250 \mathrm{~cm}^{-1}$, the $\mathrm{CH}_{2}$ wag at $\sim 1447 \mathrm{~cm}^{-1}$, and the amide I band at $\sim 1667 \mathrm{~cm}^{-1}$. Score images associated with this single factor showed a relatively uniform distribution throughout the imaged area.

Different results were obtained from the images taken at the edge of the indents. Here, two organic matrix factors were observed (Fig. 6). One represented the commonly observed Raman spectrum of bone organic matrix described above. The second factor displayed similar bands, but the amide III band showed a distinct increase in its lower-frequency component, whereas the amide I band was shifted to higher wavenumbers $\left(\sim 1678 \mathrm{~cm}^{-1}\right)$. The score images of these two factors were complementary, with the first factor having higher intensity closer to the indent and the second having higher intensity further away from the indent.

\section{Factor Analysis: Mineral Subregion}

Multiple mineral factors containing the phosphate $v_{1}$ peak in different positions were observed in most of the areas imaged (Fig. 7). It is not uncommon to observe more than one mineral factor in Raman data from a given bone specimen owing to tissue heterogeneity resulting from the aging and remodeling processes [42]. Slight local variations in the chemical composition of the mineral result in Raman spectra with varied phosphate $v_{1}$ band positions, which are easily separated by factor analysis. However, an interesting trend was observed in the entire set of images. In almost every image group, more mineral factors were observed within the indented 

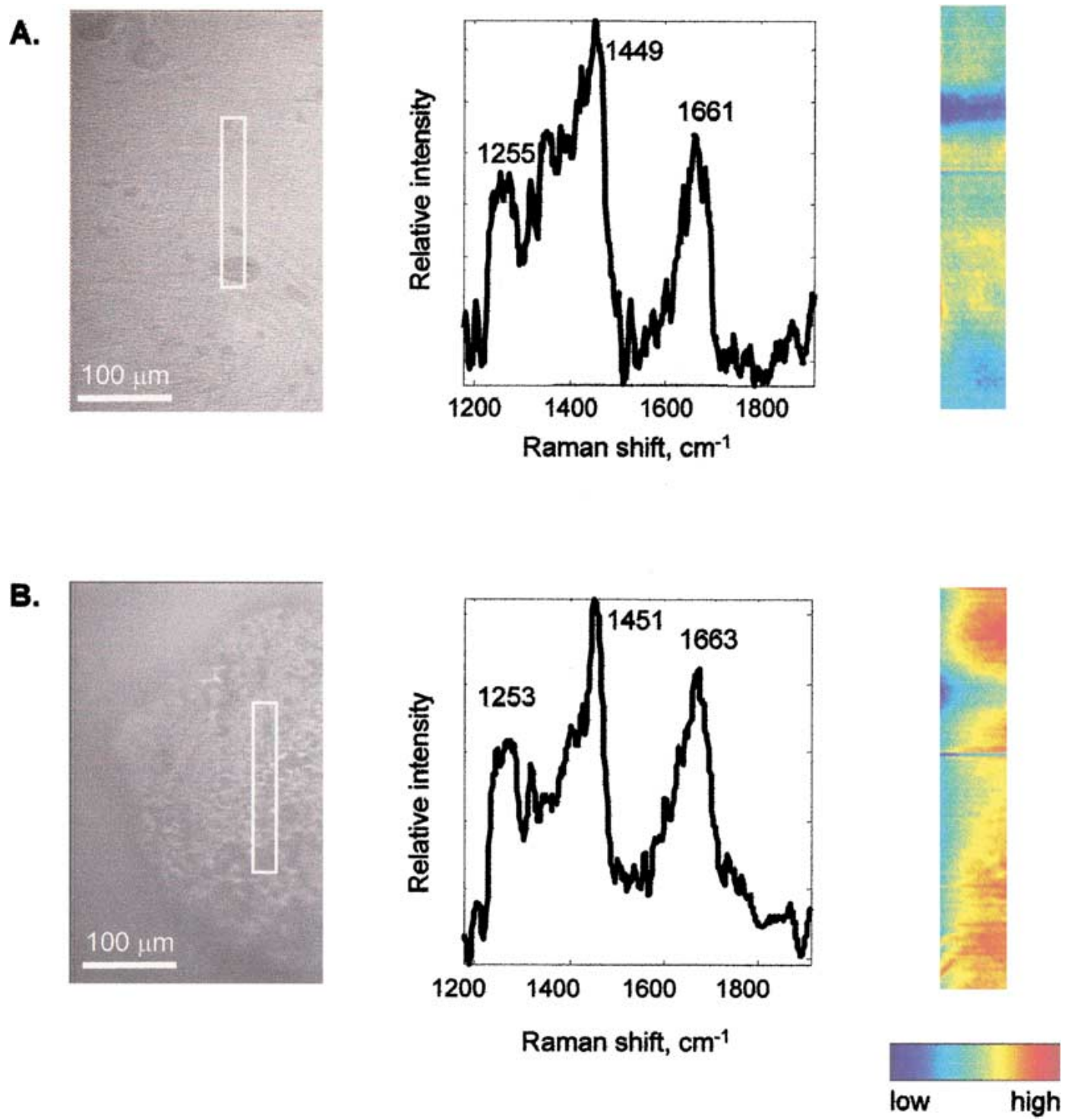

Fig. 5. Images of control regions and regions with indentations for the high-load indent on specimen \#3. (A) Brightfield image showing the control area imaged for the $230 \mathrm{~N}$ indent on specimen \#3 (the indent, which is approximately $500 \mu \mathrm{m}$ away, is out of the field of view). The white box indicates the area imaged. To the right is the single organic matrix factor ob-

area than at the edge of the indent or in the control areas. Table 1 shows these results, with the bands corresponding to new factors that appeared after indentation underlined. In most cases a lower-frequency calcium phosphate component appeared; in one case, a higher-frequency calcium phosphate component appeared. This trend is consistent with other studies from this laboratory showing an increase in the number of mineral factors present in Raman data collected from areas of damage [14, 43].

\section{Discussion}

We attribute the appearance of the additional collagen factor to damage. This factor containing shifted amide tained for this image together with its score image. (B) A single organic matrix factor is also obtained for the area imaged within the indent. Image size in both cases is approximately $200 \times 35 \mu \mathrm{m}$. For clarity, the additional background factors resulting from luminescence are not shown.

bands is indicative of the presence of collagen that has undergone a transformation from its normal triple-helical state to a disordered state, presumably as a result of the loading and deformation induced by the indentation process. The appearance of this factor is consistent with observations made by other researchers on protein films and protein solutions [19]. The higher-frequency amide I band and the lower-frequency amide III band observed in this second collagen factor are known spectral signatures of collagen in which crosslinks have been reduced or broken [44]; similar bands have also been observed in studies of collagen denaturation [45-47]. The breaking of crosslinks in mature tissue is thought to be the last process that happens before fracture [8]. 

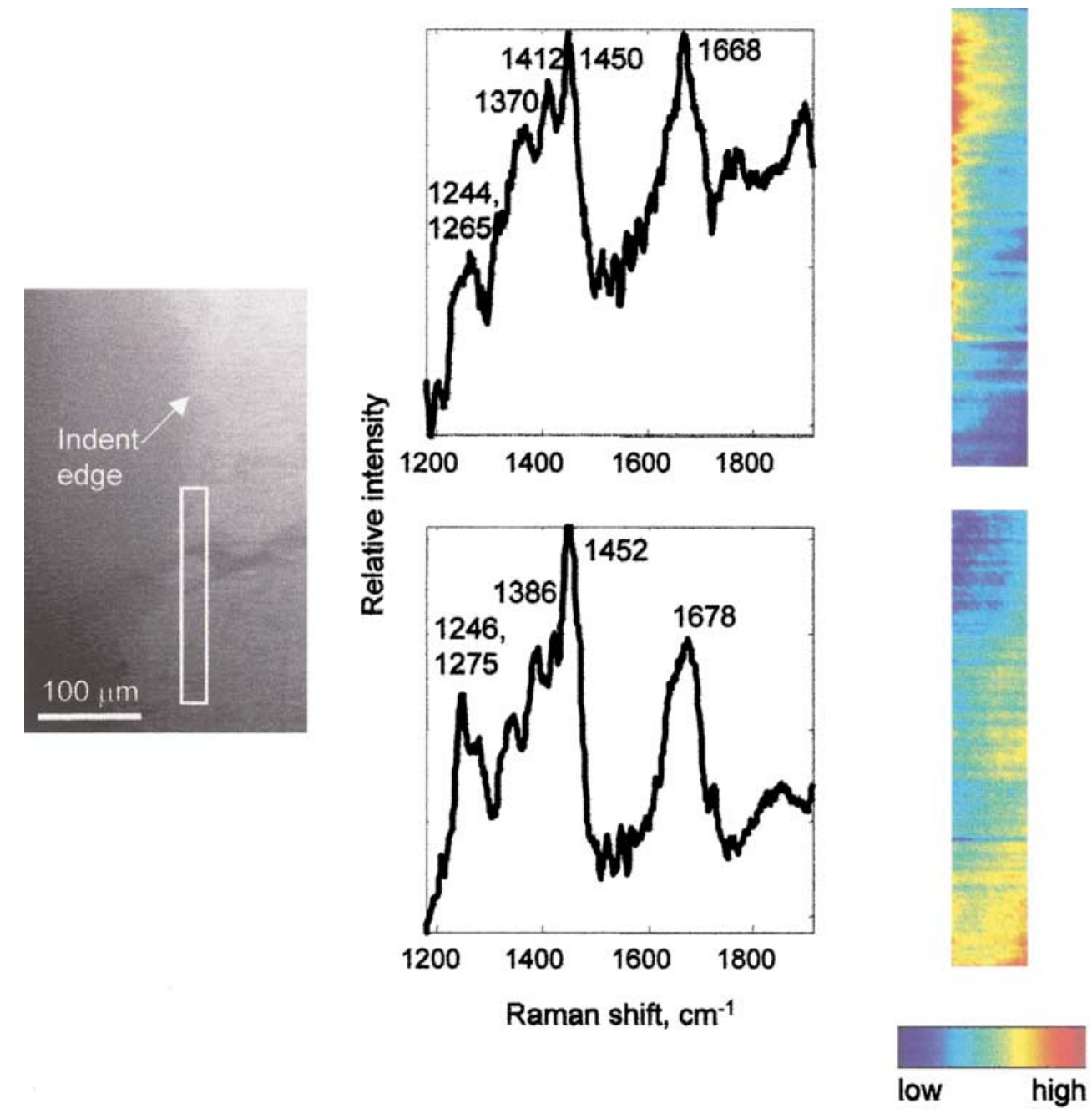

Fig. 6. Brightfield image showing the edge of the high-load indent on specimen \#3. The white box indicates the area imaged. To the right are the two organic matrix factors obtained for this image together with their score images. The factor on the top is the Raman spectrum of normal collagen. The factor on the bottom represents a Raman spectrum of disorganized collagen, showing an increase in the low frequency component

It is interesting that this damaged collagen factor is only observed at the edge of the indents, not within the indent area itself. We hypothesize that at the edge of the indents, the collagen fibrils experience shear forces caused by the edge of the indenter pushing into the bone. These shear forces cause the rupture of crosslinks. Shear behavior in the area of indentations is well characterized. For the case of a cylindrical indenter, a simple analytical description of the elastic and plastic stress field below the punch was given by Sneddon [48]. Unlike sharp indenters, friction is important for indenters that are flat or rounded. With friction, the pressure needed to penetrate to any given depth increases, and shear failure along the indenter/material interface nucleates cracks which travel outward from the compressive zone directly under the indenter [49]. These cracks are clearly visible in the SEM image of the high-load indent in Figure 4. In of the amide III band and high frequency component of the amide I band, typical of collagen that has lost its structure through crosslink rupture. Note that the score images are complementary. Image size in both cases is approximately 200 $\times 35 \mu \mathrm{m}$. For clarity, the additional background factors resulting from luminescence are not shown.

addition, closer observation of the SEM images shows the presence of a shear banding pattern at the indent edges. Similar shear banding patterns have been observed at the edges of spherical indentations [50], and shear banding and pile up at the edge of an indentation have also been generated by foreign object-induced damage in metal alloys [51]. In all these cases the material was exposed to an indenting process that allowed shearing to occur under the indent. In the case of the cylindrical punch, the complete region below the indent is subject to a compressive force limiting the appearance of local shear bands to just outside the pile-up zone at the edge of the indent. The fact that the damaged collagen factor does not appear in the data acquired from the middle of the indented area suggests that the collagen in this area is not damaged in a way that is spectroscopically visible; i.e., it is compressed but crosslinks 

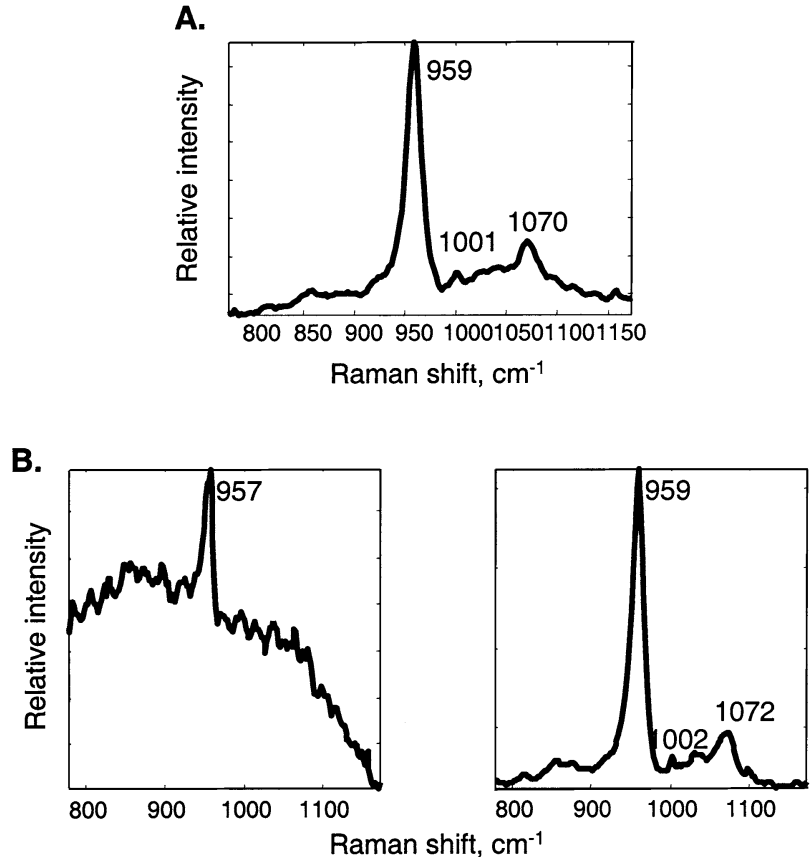

Fig. 7. Example of multiple mineral factors observed in indented specimens. (A) Single factor obtained from analysis of the control area on specimen \#3. (B) Factors representing multiple mineral factors obtained from analysis of the highload indent on specimen \#3. For clarity, the additional background factors resulting from luminescenceare not shown.

are not broken. This is consistent with the stress behavior described for cylindrical indentations.

The appearance of additional mineral factors within the indented area may indicate a pressure-induced structural transition of the mineral. The addition of either a higher- or lower-frequency component is consistent with high-pressure spectroscopy studies on calcium hydroxyapatite, which show an increase in frequency of the phosphate $v_{1}$ band followed by a decrease with increasing pressure $[23,25]$. The loads applied in this experiment result in stresses ranging from $0.4 \mathrm{GPa}$, yielding the shallow indents, to $1.2 \mathrm{GPa}$, yielding the deep indents; these values are comparable to those applied in the high-pressure spectroscopy studies in which a structural transition was observed. We therefore believe that the additional factors represent spatially distinct mineral species formed as a consequence of pressure-induced structural transitions within the bone mineral lattice [23, 25]. We have earlier observed the appearance of additional mineral factors accompanying permanent deformation in bone; for example, in the macroscopic fracture of mouse femora [43] as well as in microcracks within bovine bone [14]. However, in these studies we could not establish whether the additional mineral factors observed were a cause or an effect of the fracture process. The results from the current experiments indicate that the additional mineral factors are in fact an effect of mechanical loading. The fact that we can resolve multiple factors rather than seeing one mineral factor with a shifted phosphate $v_{1}$ band indicates that not all the mineral present undergoes the transition, possibly because the local pressure was not high enough to drive the transition to completion, or because not all the mineral species present were able to undergo the transition.

The nature of the structural transition occurring in the bone mineral is not known. Xu et al. [23] postulate that the structural transition occurring in pure hydroxyapatite is the result of a rearrangement of hydroxyl groups. However, bone mineral is thought not to contain hydroxyl groups in any appreciable concentration [52-54]. In addition, the additional substituents in bone mineral undoubtedly affect the response of the mineral to applied load. It is known that carbonation in bone mineral causes vacancies in the mineral lattice, creating an opportunity for pressure-induced movement and structural changes [53]. Further spectroscopic and X-ray diffraction studies are required to better elucidate the nature of this transformation.

\section{Conclusions}

Spectroscopic changes resulting from mechanical loading of bone were observed in these studies, indicating two different damage mechanisms for different bone tissue components. The organic matrix showed clear evidence of crosslink rupture, consistent with what is known of the mechanical behavior of other collagenous tissues, particularly more mature tissues which contain more crosslinks [8, 9]. This rupture occurred only in areas where shear forces were present (indent edges), rather than where only compression occurred (indent floor). The mineral phase of the tissue, on the other hand, was found to be altered where only compression had occurred. The possibility of a pressure-induced structural transition occurring in bone mineral is particularly intriguing. This could be a method by which energy is dissipated with minimal damage to the surrounding tissue. Similar behavior has been observed in ceramic materials subjected to stress, a phenomenon known as "transformation toughening" [55, 56]. These processes have also recently been postulated to occur in bone [57]. We propose that the bone mineral structural transitions that we have observed are the source of this transformation toughening. Aging, as well as bone diseases that alter bone mineral crystallite structure, such as osteoporosis, could hinder this transition and contribute to increased fragility. If this is the case, new and different treatment options may be realized from these results.

Acknowledgments. The authors gratefully acknowledge financial support from the following sources: Rackham Graduate School Predoctoral Fellowship (AC), the University of Michigan Bone Core Research Center (NIH grant P30 AR46024) (AC,MDM), NSF grant BES 9410303 (DHK), the Whitaker Foundation (DHK), and NIH Training Grant T32 DE 07057 (RMR). 
Table 1. Number of mineral factors, and phosphate $v_{1}$ band positions for those factors, observed for all specimens. Factors that appeared after indentation (relative to the control) are underlined.

\begin{tabular}{|c|c|c|c|c|c|c|}
\hline & \#1, low load & \#1, high load & $\# 2$, low load & \#2, high load & $\# 3$, low load & $\# 3$, high load \\
\hline Control & $\begin{array}{l}2 \text { species } \\
955 \\
959\end{array}$ & $\begin{array}{l}3 \text { species } \\
954 \\
959 \\
962\end{array}$ & $\begin{array}{l}2 \text { species } \\
959 \\
965\end{array}$ & $\begin{array}{l}1 \text { species } \\
959\end{array}$ & $\begin{array}{l}1 \text { species } \\
959\end{array}$ & $\begin{array}{l}1 \text { species } \\
959\end{array}$ \\
\hline Edge of Indent & $\begin{array}{l}\text { Not observed } \\
\text { due to fluorescence }\end{array}$ & $\begin{array}{l}1 \text { species } \\
960\end{array}$ & $\begin{array}{l}2 \text { species } \\
956 \\
960\end{array}$ & $\begin{array}{l}1 \text { species } \\
960\end{array}$ & $\begin{array}{l}1 \text { species } \\
960\end{array}$ & $\begin{array}{l}1 \text { species } \\
960\end{array}$ \\
\hline Within Indent & $\begin{array}{l}3 \text { species } \\
954 \\
957 \\
962 \\
\end{array}$ & $\begin{array}{l}2 \text { species } \\
955 \\
959\end{array}$ & $\begin{array}{l}3 \text { species } \\
\frac{954}{958} \\
962\end{array}$ & $\begin{array}{l}2 \text { species } \\
\frac{953}{959}\end{array}$ & $\begin{array}{l}2 \text { species } \\
\frac{957}{960}\end{array}$ & $\begin{array}{l}2 \text { species } \\
\frac{957}{959}\end{array}$ \\
\hline
\end{tabular}

\section{References}

1. Kaplan FS, Hayes WC, Keaveny TM, Boskey A, Einhorn JP, Iannotti JP (1994) Form and function of bone. In: Simon SR (ed) Orthopaedic basic science. American Academy of Orthopaedic Surgeons, Rosemont, Illinois, pp $127-184$

2. Rajachar RM, Chow DL, Kohn DH (2002) Incipient fatigue mechanisms in bovine cortical bone as detected by acoustic emission. J Biomech (in press)

3. Reilly GC (2000) Observations of microdamage around osteocyte lacunae in bone. J Biomech 33:1131-1134

4. Ramtani S, Zidi M (1999) Remodeling of the bone material containing microcracks: a theoretical analysis. Euro Phys J 8:257-263

5. Ascenzi A, Bonucci E (1967) The tensile properties of single osteons. Anat Record 158:375-386

6. Zysset P, Guo XE, Hoffler CE, Moore KE, Goldstein SA (1999) Elastic modulus and hardness of cortical and trabecular bone lamellae measured by nanoindentation in the human femur. J Biomech 32:1005-1012

7. Hoffler CE, Moore KE, Kozloff K, Zysset PK, Brown SA, Goldstein SA (2000) Heterogeneity of bone lamellarlevel elastic moduli. Bone 26:603-609

8. Silver FH, Kato YP, Ohno M, Wasserman AJ (1992) Analysis of mammalian connective tissue: relationship between hierarchical structures and mechanical properties. J Long-Term Effects Med Implants 2:165-198

9. Fratzl P, Misof K, Zizak I, Rapp G, Amenitsch H, Bernstorff S (1997) Fibrillar structure and mechanical properties of collagen. J Struct Biol 122:119-122

10. Carden A, Morris MD (2000) Application of vibrational spectroscopy to the study of mineralized tissues (review). J Biomed Optics 5:259-268

11. Magne D, Weiss P, Bouler J-M, Laboux O, Daculsi G (2001) Study of the maturation of the organic (type I collagen) and mineral (nonstoichiometric apatite) constituents of a calcified tissue (dentin) as a function of location: a Fourier transform infrared microspectroscopic investigation. J Bone and Miner Res 16:750-757

12. Ou-Yang H, Paschalis EP, Mayo WE, Boskey AL, Mendelsohn R (2001) Infrared microscopic imaging of bone: spatial distribution of $\mathrm{CO}_{3}^{2-}$. J Bone Miner Res 16:893-900

13. Gadaleta SJ, Boskey AL, Paschalis E, Carlson C, Menschik F, Baldini T, Peterson M, Rimnac CM (2000) A physical, chemical, and mechanical study of lumbar vertebrae from normal, ovariectomized, and nandrolone decanoate-treated cynomolgus monkeys (Macaca fascicularis). Bone 27:541-550

14. Timlin JA, Carden A, Morris MD, Rajachar RM, Kohn DH (2000) Raman spectroscopic imaging markers for fatigue-related microdamage in bovine bone. Analyt Chem 72:2229-2236
15. Timlin JA, Morris MD, Bonadio JF, Hoffler ICE, Kozloff SA, Goldstein SA (1999) Spatial distribution of phosphate species in mature and newly generated mammalian bone by hyperspectral Raman imaging. J Biomed Optics 4:2834

16. Pezzuti JA, Morris MD, Bonadio JF, Goldstein SA (1998) Hyperspectral Raman imaging of bone growth and regrowth chemistry. Proc of the SPIE 3261:270-276

17. Yeh W-Y, Young RJ (1998) Deformation processes in poly(ethyleneterephthalate) fibers. J Macromol Sci Phys B37:83-118

18. Yeh W-Y, Young RJ (1999) Molecular deformation processes in aromatic high modulus polymer fibers. Polymer 40:857-870

19. Frushour BG, Koenig JL (1974) Raman spectroscopic study of mechanically deformed poly-L-alanine. Biopolymers 13:455-474

20. Renugopalakrishnan V (1985) Low-frequency Raman spectra as a conformational probe for polypeptides and proteins. Macromolecules 18:1786-1788

21. Bandekar J (1992) Amide modes and protein conformation. Biochim Biophys Acta 1120:123-143

22. Kailer A, Nickel KG, Gogotsi YG (1999) Raman microspectroscopy of nanocrystalline and amorphous phases in hardness indentations. J Raman Spectroscopy 30:939946

23. Xu J, Gilson DFR, Butler IS, Stangel I (1996) Effect of high external pressures on the vibrational spectra of biomedical materials: calcium hydroxyapatite and calcium fluorapatite. J Biomed Mater Res 30:239-244

24. Butler IS, Gilson DFR (1997) Recent studies of the highpressure vibrational microspectra of solid inorganic materials. J Mol Struct 408/409:39-45

25. Vaidya SN, Karunakaran C, Pande BM, Gupta NM, Iyer SB, Karweer SB (1997) Pressure-induced crystalline to amorphous transition in hydroxylapatite. J Mater Sci 32:3213-3217

26. Morris MD, Carden A, Rajachar RM, Kohn DH (2001) Bone microstructure deformation observed by Raman spectroscopy. Proc SPIE 4254:81-89

27. Gustafson MB, Martin RB, Gibson V, Storms DH, Stover J, Gibeling J, Griffin L (1996) Calcium buffering is required to maintain bone stiffness in solution. $\mathrm{J}$ Biomech 29:1191-1194

28. Christensen K, Morris MD (1998) Hyperspectral Raman microscopic imaging using Powell lens line illumination. Appl Spectroscopy 52:1145-1147

29. Jestel NL, Shaver JM, Morris MD (1998) Hyperspectral Raman line imaging of an aluminosilicate glass. Appl Spectroscopy 52:64-69

30. Zhang D, Hanna JD, Jiang Y, Ben-Amotz D (2001) Influence of laser illumination geometry on the power distribution advantage. Appl Spectroscopy 55:61-65 
31. Carden A (2002) Effects of applied load on bone ultrastructure explored using Raman microspectroscopy and imaging. Ph.D. dissertation, University of Michigan, Ann Arbor, Michigan

32. Boskey AL, Camacho NP, Mendelsohn R, Doty SB, Binderman I (1992) FT-IR microscopic mappings of early mineralization in chick limb bud mesenchymal cell cultures. Calci Tissue Int 51:443-448

33. Bussian BM, Sander C (1989) How to determine protein secondary structure in solution by Raman spectroscopy: practical guide and test case DNase I. Biochemistry 28:4271-4277

34. Adams MJ (1995) Chemometrics in analytical spectroscopy. The Royal Society of Chemistry, Cambridge

35. Grahn H, Szeverenyi NM, Roggenbuck MW, Delaglio F, Geladi P (1989) Data analysis of multivariate magnetic resonance images. I. A principal component analysis approach. Chemometrics and Intelligent Laboratory Systems 5:311-322

36. Geladi P, Grahn H (1996) Multivariate image analysis. John Wiley and Sons, Chichester

37. Geladi P, Isaksson H, Lindqvist L, Wold S, Esbensen K (1989) Principal components analysis of multivariate images. Chemomet Intel lab systems 5:209-220

38. Kawata, Satoshi, Sasaki, Keiji (1996) Multispectral image processing for data analysis. In: Wang X.F., Herman B. (eds) Fluorescence imaging spectroscopy and microscopy. John Wiley and Sons, NY, pp 55-85

39. Drumm CA, Morris MD (1995) Microscopic Raman lineimaging with principal components analysis. Applied Spectroscopy 49:1331-1337

40. Shaver JM, Christensen KA, Pezzuti JA, Morris MD (1998) Structure of dihydrogen phosphate ion aggregates by Raman-monitored serial dilution. Appl Spectroscopy 52:259-264

41. Morris MD, Timlin JA, Garden A, Tarnowski CP, Edwards CM (2000) Multivariate data reduction techniques for hyperspectral Raman imaging. Proc SPIE 3920:151158

42. Tarnowski CP, Ignelzi Jr MA, Morris MD (2002) Mineralization of developing mouse calvaria as revealed by Raman microspectroscopy. J Bone Miner Res 17:1118-1126

43. Morris MD, Carden A, Rajachar RM, Kohn DH (2002) Effects of applied load on bone tissue as observed by Raman spectroscopy. Proc SPIE 4614:47-54
44. Paschalis EP, Verdelis K, Doty SB, Boskey AL, Mendelsohn R, Yamauchi M (2001) Spectroscopic characterization of collagen crosslinks in bone. J Bone Miner Res 16:1821-1828

45. Lazarev YA, Lazareva AV (1978) Infrared spectra and structure of synthetic polypeptides. Biopolymers 17:11971214

46. Lazarev YA, Grishovsky BA, Khromova TB (1985) Amide I band of IR spectrum and structure of collagen and related polypeptides. Biopolymers 24:1449-1478

47. Frushour BG, Koenig JL (1975) Raman scattering of collagen, gelatin, and elastin. Biopolymers 14:379-391

48. Sneddon IN (1965) The relation between load and penetration in axisymmetric Boussinesq problem for a punch of arbitrary profile. Int J Eng Sci 3:47-57

49. Baran G, Shin W, Abbas A, Wunder S (1994) Indentation cracking of composite matrix materials. J Dent Res 73:1450-1456

50. Guiberteau F (1993) Indentation fatigue. A simple cyclic Hertzian test for measuring damage accumulation in polycrystalline ceramics. Philos Mag A 68:1003-1016

51. Ritchie RO (1999) Thresholds for high-cycle fatigue in a turbine Engine Ti-6A1-4V alloy. Int J Fatigue 21:653662

52. Rey C, Collins B, Goehl T, Dickson IR, Glimcher MJ (1989) The carbonate ion environment in bone mineral: a resolution-enhanced Fourier transform infrared spectroscopy study. Calcif Tissue Int 45:157-164

53. Rey C, Miquel JL, Facchini L, Legrand AP, Glimcher MJ (1995) Hydroxyl groups in bone mineral. Bone 16:583586

54. Loong C-K, Rey C, Kuhn LT, Combes C, Wu Y, Chen S-H, Glimcher MJ (2000) Evidence of hydroxyl-ion deficiency in bone apatites: an inelastic neutron-scattering study. Bone 26:599-602

55. Belnap JD, Tsai J-F, Shetty DK (1994) Direct measurement of crack shielding in ceramics by the application of Raman microprobe spectroscopy. J Mat Res 9:31833193

56. Green DJ, Hannink RHJ, Swain MV (1989) Transformation toughening of ceramics. CRC Press, Inc., Boca Raton, FL

57. Vashishth D, Behiri JC, Bonfield W (1997) Crack growth resistance in cortical bone: concept of microcrack toughening. J Biomech 30:763-769 